Imágenes de la juventud en contextos «rurbanos»

Esau Salvador Bravo Luis, Pamela Estefanía Martínez Espinoza

Revista Argentina de Estudios de Juventud, (15), e065, 2021

ISSN 1852-4907 | https://doi.org/10.24215/18524907e065

https://perio.unlp.edu.ar/ojs/index.php/revistadejuventud

FPyCS | Universidad Nacional de La Plata

La Plata | Buenos Aires | Argentina

\title{
IMÁGENES DE LA JUVENTUD EN CONTEXTOS «RURBANOS»
}

\author{
Images of Youth in «Rurban» Contexts
}

Esau Salvador Bravo Luis

esaubravo@uadec.edu.mx

https://orcid.org/0000-0002-5005-0693

Pamela Estefanía Martínez Espinoza

pamelamartinez@uadec.edu.mx

https://orcid.org/0000-0003-1006-0106

Facultad de Ciencias de la Comunicación

Universidad Autónoma de Coahuila

México

\section{Palabras clave \\ juventud rural tecnología \\ usos sociales} imágenes urbanas

\section{Resumen}

Jóvenes y adultos/as comparten perfiles socioeconómicos y laborales dentro de una comunidad ejidal al norte de México. Si bien dichas actividades determinan su vínculo con el ejido, es la falta de escucha entre ellos/as lo que los/as distancia. En este escenario, reflexionamos sobre dos componentes interrelacionados entre sí al vector tecnológico: juventud-adultez y ejido-ciudad. Las diferencias detectadas en el trabajo de campo ofrecen un escenario fértil para identificar posibles soluciones comunicativas ante el desencuentro de estas dos generaciones.

\section{Abstract}

Keywords

Young people and adults share socioeconomic and work profiles within an ejido community in northern Mexico. While these activities determine their link with the ejido, it is the lack of listening to each other that distances them. In this scenario, we reflect on two interrelated components to the technological vector: youth-adulthood and ejido-city. The differences detected in the field work will be a fertile scenario that helps to identify possible communicative solutions to the disagreement between these two generations.

Recibido 13/08/2021 Aceptado 24/10/2021 Publicado 22/12/2021 


\title{
IMÁGENES DE LA JUVENTUD EN CONTEXTOS «RURBANOS»
}

\author{
Por Esau Salvador Bravo Luis \\ y Pamela Estefanía Martínez Espinoza
}

\section{Introducción}

El presente texto presenta los primeros avances del trabajo realizado por el equipo de investigación del proyecto «Comunidades Emergentes de Conocimiento y Procesos de Investigación/Creación Audiovisual», financiado por el Consejo Nacional de Ciencia y Tecnología (CONACYT), ${ }^{1}$ que inició en octubre de 2019 y culminará en octubre de 2022. Desde hace dos años, en el norte de México, tres investigadores y seis estudiantes de dos universidades integran un equipo de investigación interdisciplinario que trabaja a través de metodologías participativas con los/as jóvenes estudiantes de bachillerato. Los/as integrantes del equipo pertenecen a la Facultad de Ciencias de la Comunicación de la Universidad Autónoma de Coahuila (UADEC) y a la carrera de Ingeniería en Desarrollo Rural de la Universidad Autónoma Agraria Antonio Narro (UAAAN).

El objetivo del trabajo colectivo es establecer y fortalecer diálogos intergeneracionales entre dicha comunidad estudiantil y los habitantes más viejos del ejido; pues, pues, pareciera que los/as más jóvenes no están comprometidos/as con la defensa de los derechos de la tierra y el agua, asuntos sustanciales para preservar la forma de vida de esta comunidad.

Desde los primeros acercamientos al trabajo de campo, se detectó el uso de la tecnología interconectada a la red como un factor preponderante entre estos dos grupos; que si bien son distintos en términos de rangos etáreos, son muy similares 
en cuanto a las necesidades de uso, tanto de los dispositivos como de los servicios de comunicación. En términos de comunicación, el dispositivo electrónico es un artefacto comunicante que es empleado por los/as jóvenes de Jalpa, esencialmente, para el entretenimiento, mientras que los/as adultos/as lo utilizan como una herramienta de trabajo y de denuncia. De este modo, entendemos que el acceso y el uso son determinantes en la construcción de una posible instancia de transformación tecnológica (Berardi, 2017); es decir, complementar la triada acceso-uso-apropiación, por la tétrada que incluye un proceso de transformación, pues las diferentes formas de utilizar la tecnología para mostrar el ejido son también modos que posibilitan la apropiación del territorio.

Keith Moxey (2015) refiere que las imágenes y el mundo no establecen una sola forma de exponer aquello que se mira; por lo tanto, debemos hablar de diferentes tiempos y lugares que se intersecan y se yuxtaponen formando parte del tiempo que todos habitamos. El tiempo es imponderable, es la totalidad de lo que ocurre en la vida de sus protagonistas. En este sentido, las prácticas que estos/as jóvenes y adultos/as realizan para mostrar al ejido -tanto a través de los dispositivos tecnológicos como mediante objetos analógicos- son posibilidades que se despliegan desde las actividades de su vida cotidiana. Muchas de ellas las hemos rescatado en las bitácoras de trabajo desde las metodologías participativas y las entendemos como acciones políticas que nacen, sobre todo, de todo aquello que sus habitantes le interpelan al territorio que habitan.

En Jalpa, jóvenes y adultos/as comparten perfiles socioeconómicos y laborales. No obstante, aunque realizan sus actividades cotidianas en conjunto -las laborales, principalmente-, y son estas las que en buena medida determinan su vínculo con el ejido, es la falta de escucha lo que los/as distancia. Este modelo de vida presupone la selección y la imposición de una posibilidad entre muchas y, por lo tanto, la simultánea exclusión de otras (Berardi, 2017). Pese a esto, sus actividades y sus formas de relacionarse no pueden ser como acciones homogéneas en las que se establezca una ponderación lineal que determine de una única manera su relación con el territorio. En este sentido, las diferencias detectadas serán no el problema, sino el vínculo que permita establecer posibles soluciones al desencuentro entre las dos generaciones en conflicto. 
Finalmente, este texto abona los aportes reflexivos sobre el estudio de la juventud rural en México, pues la escasez de literatura especializada -principalmente, la que indaga sobre sus formas de vida- dificulta establecer con claridad un marco de referencia que nos permita apoyarnos en los debates propuestos con anterioridad. Ante este escenario, coincidimos con Lourdes Pacheco Ladrón (2013) quien señala que «la juventud rural en México ha sido escasamente estudiada debido a su ocultamiento [e invisibilización] en la categoría de juventud» (p. 19, en Corduneanu, 2017, p. 28). Esto sucede, por un lado, porque estos estudios, en su mayoría, responden a la necesidad de generar relevamientos sobre los contextos urbanos de los/as jóvenes; por otro, porque, generalmente, se consideraba los/as jóvenes rurales «en tránsito hacia la urbanización, pero no como sujetos portadores de un proyecto de sociedad en sí misma» (Pacheco Ladrón, 2013, p. 19, en Corduneanu, 2017, p. 28).

No obstante, es indispensable entender que en asentamientos cercanos a las grandes urbes la condición de ruralidad sí propicia un desdibujamiento de las fronteras entre lo rural y lo urbano, pues la constante presencia de lo que acontece en la ciudad permea muchas de las actividades cotidianas de los/as habitantes del ejido y, en no pocas ocasiones, las formas mediante las cuales se expresa lo citadino se convierten en un eje articulador de sus acciones, sentires y deseos. Stefano Micheletti, Felipe Saravia y Francisco Letelier (2019) refuerzan esta postura al señalar que el joven rural mantiene una condición inter configurada por elementos que son parte urbanos y parte rurales. La información relevada por los autores durante el trabajo realizado en Maule, al norte de Chile, identifica que los pobladores de esta comuna se definen como rurbanos, una categoría que, en el caso de nuestro estudio, permite guiarnos con mayor claridad para identificar los elementos que se manifiestan en las prácticas urbanas y rurales dentro del grupo de estudiantes y de adultos/as del ejido.

\section{Jalpa, sus actores y sus prácticas}

Fundado en 1936, el ejido Jalpa se ubica en el municipio de General Cepeda, Coahuila, en el noreste de México [imagen 1]. De acuerdo al Instituto Nacional de Estadística y Geografía (INEGI, 2015), cuenta con una población de 252 habitantes de los cuales $54 \%$ son hombres y 46\% mujeres. Protegido por la Ley Agraria Mexicana (1992), 
el ejido se encuentra facultado para establecer con total independencia su propia organización social y económica, así como para definir lineamientos propios sobre la disposición de las tierras que se consideran de uso común. En términos territoriales, aunque su extensión total supera las 6.500 hectáreas, el casco habitado ocupa menos de una y se reduce, apenas, a 60 viviendas (INEGI, 2015).

Su organización política se establece a partir de tres órganos internos: el órgano supremo es la Asamblea, seguida por el Comisariado Ejidal y por el Consejo de Vigilancia. El primer organismo, la Asamblea, debe estar integrado por todos los/as ejidatarios/as, según lo dicta el artículo 21 de la Ley Agraria Mexicana, cuya última actualización fue en 1992. Sin embargo, los/as integrantes de los tres órganos internos superan los 50 años y ninguno cuenta con la participación de jóvenes.

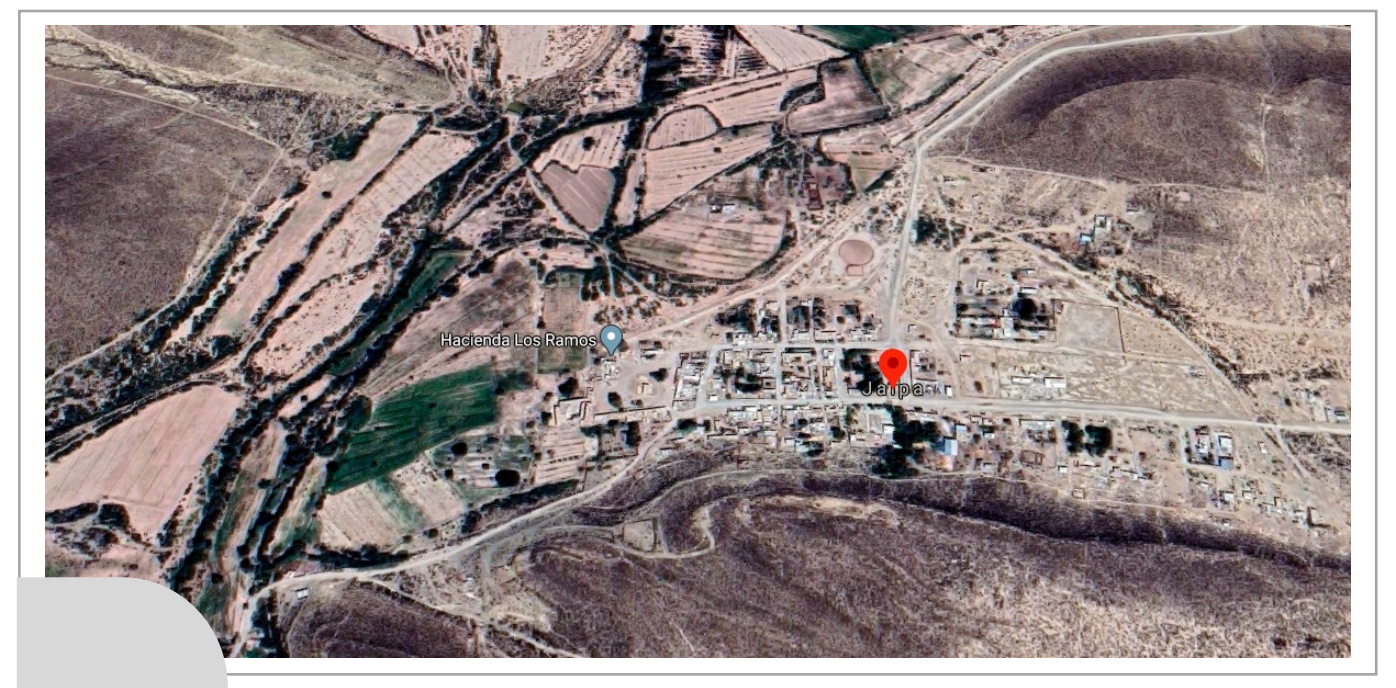

Imagen 1 | Imagen satelital de Jalpa, Coahuila, registrada en julio de 2020. Fuente: Google Maps

Ante este escenario, reflexionamos sobre dos componentes interrelacionados entre sí y con el vector tecnológico: juventud-adultez y ejido-ciudad. El primero, juventudadultez, está integrado por dos categorías que entendemos desde la noción de disputa. Para su análisis, partimos de las prácticas específicas que estos dos sectores desempeñan tanto en el ejido como fuera de él y tomamos fragmentos de sus opiniones -rescatadas durante la primera parte del trabajo de campo-, desde las cuales analizamos: los diálogos expresados en las derivas ${ }^{2}$ por el ejido, los mapas elaborados en los talleres de cartografía y los relatos construidos en la producción de videos colectivos. 
El segundo componente, ejido-ciudad, es analizado desde los imaginarios que representaron los/as estudiantes y los/as adultos a través de las imágenes generadas en los mencionados ejercicios. Para esto, recurrimos a la construcción de mapas colectivos, a partir de unir los mapas individuales y de yuxtaponerlos para resaltar cuáles son los elementos comunes presentes en las cartografías. Esta actividad nos permitió identificar los escenarios y los lugares más valorados durante las derivas, así como los oficios y las actividades que jóvenes y adultos/as detectan como fundamentales en el ejido.

Finalmente, observamos estos dos conjuntos de análisis a través de una matriz de uso de la tecnología interconectada, pues ambos grupos utilizan la telefonía celular, los servicios de Internet y las redes sociales para narrar su vida y para exponer su propia idea de territorio y de pertenencia al ejido. De este modo, desde la observación y el diálogo detectamos que estas actividades aparentemente distintas entre jóvenes y adultos/as son profundamente similares y podrían, en esta medida, ser el vínculo que estreche las relaciones intergeneracionales en el ejido.

\section{Metodología}

Para realizar el trabajo de campo, se recurrió a diferentes técnicas de InvestigaciónAcción-Participativa con el objetivo de establecer un diálogo directo entre quienes habitan el ejido y quienes integran el equipo de investigación. Este posicionamiento teórico y metodológico, pero sobre todo humano, nos obliga a entendernos, en primer lugar, como sujetos políticos y, después, como un colectivo de trabajo. Asimismo, nos permite alejarnos de las mediciones clásicas y verticales del paradigma estructural funcionalista; pues, ante todo, buscamos entender junto con quienes habitan el ejido cuáles son las problemáticas a las que nos enfrentamos desde el saber y el sentir de los sujetos y, con ello, lograr gestionar conocimientos colectivos.

Desde esta perspectiva, también nos obligamos a situar a las ciencias sociales al servicio de la transformación social, para construir escenarios en donde emerjan con mayor claridad otros actores protagónicos desde un lugar que se aleje de la noción de periferia y que los sitúe como actores centrales desde un núcleo catalizador de múltiples saberes y formas de vida. Nos referimos, específicamente, a los/as pobladores del ejido, habitantes de una región que se ubica en el ámbito rural pero 
que mantiene un constante diálogo-dependencia con los contextos urbanos, característica que les permite a sus habitantes desplazarse entre ellos y reconfigurar, constantemente, sus patrones identitarios. Así, el concepto rurbano (Micheletti, Saravia \& Letelier, 2019) se entiende desde el movimiento y las trayectorias que realizan los sujetos para elaborar los imaginarios que expresan a través de las imágenes que construyen sobre el lugar que habitan.

El objetivo de los ejercicios realizados con los/as estudiantes de bachillerato radicó en observar, sentir y conocer. Para ello, se llevaron a cabo tres actividades específicas que parten de las metodologías participativas: realizar transectos o derivas por el ejido en los cuales los/as jóvenes fungieron como guías; construir una "red de sentires» dentro del aula de clase; elaborar un video en equipo para mostrar, desde su propia mirada, qué es lo más importante de Jalpa.

\section{Las derivas}

Los primeros vínculos con los/as estudiantes surgieron rápidamente. En el caso de las derivas, a través de su propia voz los/as jóvenes narraron los diferentes recorridos, que incluían parte de la vida diaria en el ejido. Los trayectos realizados se recrearon sobre papel para mostrar las rutas que transitan desde su casa a la escuela, identificando los lugares que les resultaban más significativos del ejido. Una vez terminados, los mapas se colocaron en el suelo y se unieron para observar cómo al juntarlos se construye y se identifica, desde cada mirada individual, el territorio colectivo [imágenes 2].

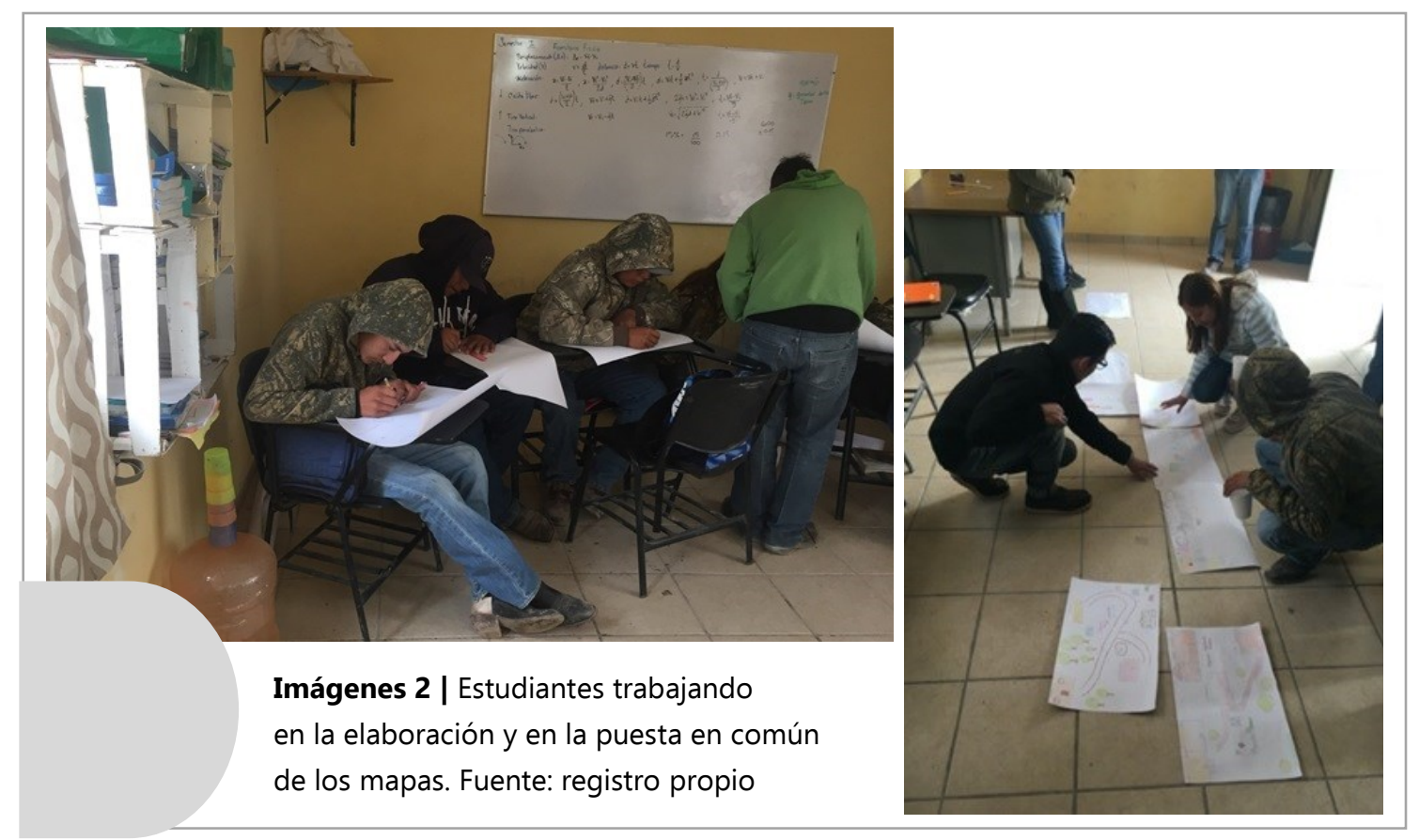


Esta cartografía, generada a través de la mirada de los/as estudiantes, ayudó a elaborar una contra-cartografía de Jalpa, pues para localizar y para conocer el ejido a través de información oficial solo se cuenta con imágenes satelitales. Dado que prácticamente no existen imágenes que muestren el interior del ejido, los mapas de los/as estudiantes permiten mostrar una geografía que se articula desde la mirada colectiva de sus habitantes [imagen 3].

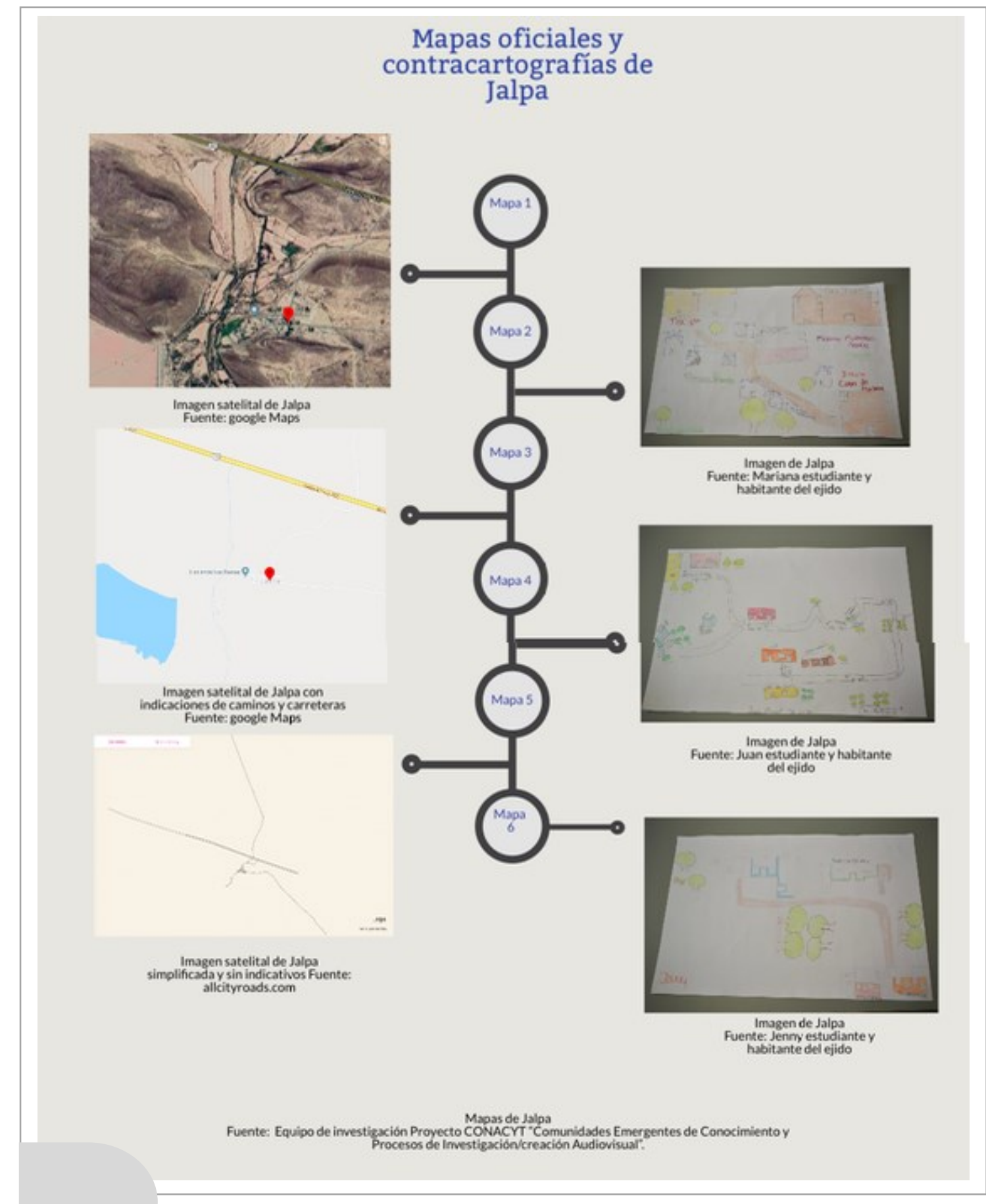

Imagen 3 | Comparativo de mapas de Jalpa, Coahuila. Fuente: registro propio 


\section{La «red de sentires»}

Para visualizar las relaciones afectivas entre los recorridos por el ejido recurrimos a la «red de sentires», actividad que se realiza con la ayuda de una cuerda. Como se muestra en la imagen 4, los/as estudiantes toman un extremo y entregan el otro al alguien con quien comparten gustos, afinidades, recuerdos y experiencias positivas. El ejercicio se realiza estableciendo líneas rectas y al finalizar el intercambio es posible observar que todos/as se encuentran estrechamente relacionados/as, no solo por el espacio que tienen en común sino por las experiencias y las vivencias que han compartido dentro del ejido.

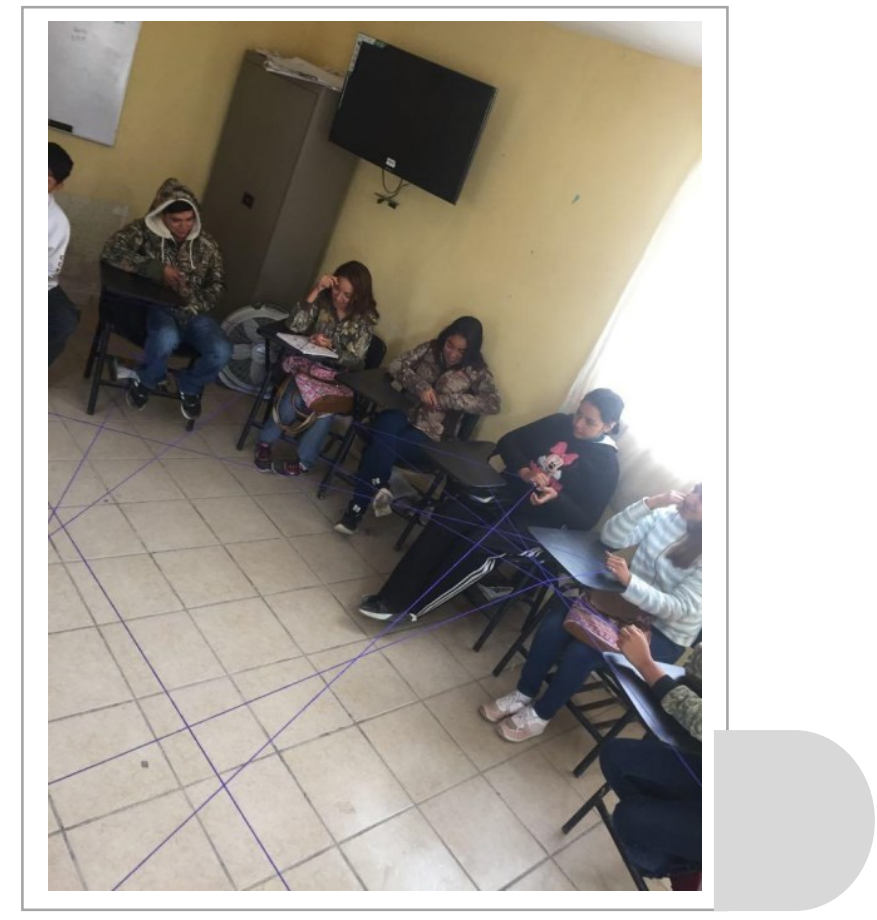

Imagen 4 | Estudiantes trabajando en la «red de sentires» Fuente: registro propio

\section{El video colectivo}

La tercera actividad se realizó a través del video colectivo. Para llevarlo a cabo, se organizaron tres grupos de grabación a los cuales se les entregó un kit básico de cámara y micrófono; la explicación sobre el funcionamiento básico del equipo estuvo a cargo de estudiantes de la Facultad de Comunicación. Una vez dadas las instrucciones, cada grupo elaboró un guion sobre la historia de un lugar o de una actividad del ejido. La elección de la temática fue libre y se elaboraron tres videos que narran tres historias: de la iglesia, de «la casa grande» y del proceso de tallado de la lechuguilla 3 [imágenes 5]. 
Con la realización de este ejercicio comenzaron a ser evidentes los conocimientos que los/as estudiantes tienen tanto de la historia del ejido como de los oficios de Jalpa, que, en sus palabras, solo son reconocidos como el trabajo de los/as adultos/as. Esto último se debe a que su participación en las labores productivas no está plenamente reconocida, incluso pese a que tienen un dominio pleno de todo el proceso, que comprende la ubicación del lugar en el que se recolecta la materia prima, la elección adecuada de cada planta y el proceso de tallado para transformarla en insumo para la industria manufacturera de la ciudad de Saltillo.

Respecto de los aspectos histórico-culturales, los/as jóvenes narraron con certeza algunas de las historias y las leyendas del ejido; los años de fundación de las iglesias y los «milagros» que han acontecido en Jalpa; quiénes han sido los dueños de «la casa grande» y las consecuencias económicas que la mantienen, en la actualidad, al borde de la ruina por el abandono y la falta de mantenimiento.

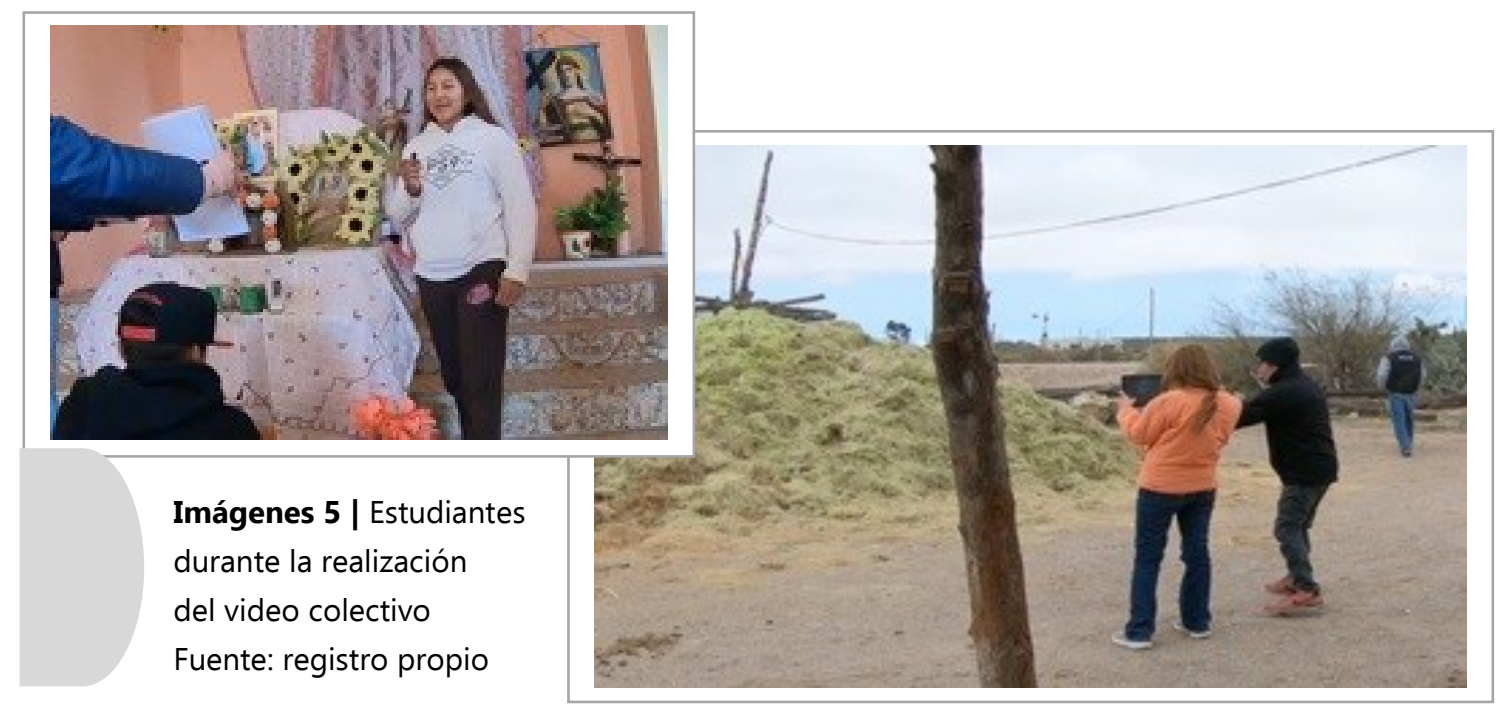

Con las cartografías basadas en las derivas por el ejido, los ejercicios de la red de sentires y la producción de videos sobre lo que consideran más relevante de Jalpa, los/as jóvenes mostraron múltiples caras tanto del ejido como del compromiso con el territorio, algo que en voz de los/as adultos/as -aparentemente- no tienen. Sin embargo, para ellos/as el ejido debe entenderse como un espacio que desdobla la noción de pertenencia adultocéntrica, pues los/as jóvenes expresan esa pertenencia de formas distintas respecto a los/as adultos/as.

Los/as jóvenes de Jalpa sienten un profundo respeto por el ejido, y lo idealizan desde sus propios deseos, aquellos que construyen colectivamente con sus iguales 
y a partir de las miradas de nostalgia que elaboran sobre su terruño cuando están fuera de él. Esto ocurre no solo cuando salen físicamente del territorio para asistir a los bailes en la ciudad más cercana, sino también cuando navegan por la red y observan que existen otras formas de habitar y de co-construir su espacio de vida, pues con estos referentes ellos configuran sus modos de ser y de estar en el ejido.

\section{Realidades paralelas: \\ ser joven y adulto, urbano y rural}

Siguiendo a Micheletti, Saravia y Letelier (2019), el/la joven rural también construye sus procesos identitarios con miradas urbanas. Físicamente, lo hace desde la indumentaria, mediante la elección de colores y en la imitación a través de patrones de combinación de su ropa. Al observarlos con sudaderas de capucha y patrón de camuflaje se les preguntó por qué vestían de esa forma y, casi al unísono y entre risas, respondieron: «Es la moda de acá». Sin embargo, cuando realizamos la misma pregunta a uno de los líderes ejidales respondió: «Es la moda de muchos en el rancho... Quieren parecer ganaderos y por eso se visten así. Aunque solo tengan una vaca quieren parecerse a los ganaderos de la laguna». ${ }^{4}$

Los/as jóvenes de Jalpa no viven una realidad distinta a la de los/as jóvenes urbanos/as, que asumen su estatus de juventud a través de agrupaciones a las que Juan Claudio Silva denomina tribus (2002), y que, para el caso de Jalpa, se conforman entre iguales. En las dinámicas de trabajo, visualizamos una división entre hombres y mujeres y asumimos a qué grupo pertenecían a partir de su peculiar forma de vestir.

Las identidades del/la joven rural surgen, y son similares a las de un/a joven urbano/a: a pesar de la distancia y las diferencias, construyen una identidad personal y al mismo tiempo colectiva. Sin embargo, este ideal se ve desdibujado cuando en las prácticas diarias se observan acciones que no diferencian las actividades adultas de las juveniles. Este posicionamiento nos permite entender a la juventud como un estadio biográfico socialmente construido (Feixa, 2003) y como un grupo social en el que se concentran sueños, motivaciones, preocupaciones, esperanzas y, sobre todo, imaginarios sobre un mundo adulto plagado de roles que 
indiscutiblemente son negados, pero que están obligados a asumir y, finalmente, a comprender.

En Jalpa, el salto biológico de niño/a a joven y de joven a adulto/a no se produce en forma clara, pues los roles para que la comunidad sobreviva son asumidos por todos/as sin importar la edad. La labor en el campo es actividad de hombres mientras que las tareas del hogar son exclusivas de mujeres. En este punto, los/as jóvenes, casi niños/as, asumen su papel y son considerados/as «como sujetos aptos para la reproducción de la sociedad en la que se encuentran insertos» (Silva, 2002, p. 119).

En la respuesta juvenil a las grandes corrientes culturales hegemónicas, observamos que es intuitiva, en algunos casos, e iterativa y sistemática en otros. También advertimos que los/as jóvenes buscan reconstruir lazos rotos o perdidos, producto de los fenómenos mundiales de modernización, y lo hacen desde lo que mejor conocen: mediante una vuelta a lo tribal (Silva, 2002), en el sentido de una mayor incidencia de lo emocional-afectivo, de aquello que es propio de la comunidad de hermanos/as y de iguales, que comparten un destino y una finalidad común.

En este sentido, Jalpa no es rural ni urbano, sus habitantes mantienen activa una mezcla de ambos entornos. Esta amalgama se observa en las prácticas sociales y en las condiciones de infraestructura en las que viven sus habitantes. ${ }^{5}$ Por caso, al tiempo que poseen caballos y mulas para desplazarse dentro del ejido y a las comunidades vecinas, también tienen grandes camionetas pick-up con las que se trasladan por las autopistas a las ciudades más cercanas para comercializar sus productos. Del mismo modo, al tiempo que poseen televisores antiguos -en algunos casos, aún con cinescopio-, muchos/as cuentan con teléfonos celulares modernos y perfiles en redes sociales.

El imaginario de la ciudad está siempre presente en sus habitantes. En los/as más jóvenes, dicho imaginario se fortalece cuando asisten a los bailes que se llevan a cabo en Saltillo, la ciudad más próxima al ejido y una de las más importantes del país para la industria automotriz y manufacturera de alta calidad. Este escenario urbano les resulta seductor, no solo porque se ha convertido en el centro de diversión y de entretenimiento que los aleja -al menos, en forma momentáneadel control parental del ejido, sino porque les permite formar parte del escenario citadino y moderno. 
No obstante, aunque para sus actividades de recreación se trasladan a la ciudad, mantienen siempre un vínculo permanente con el ejido; por ejemplo, al destacar su lugar de origen en los momentos de socialización que se producen en los sitios de divertimento que frecuentan.

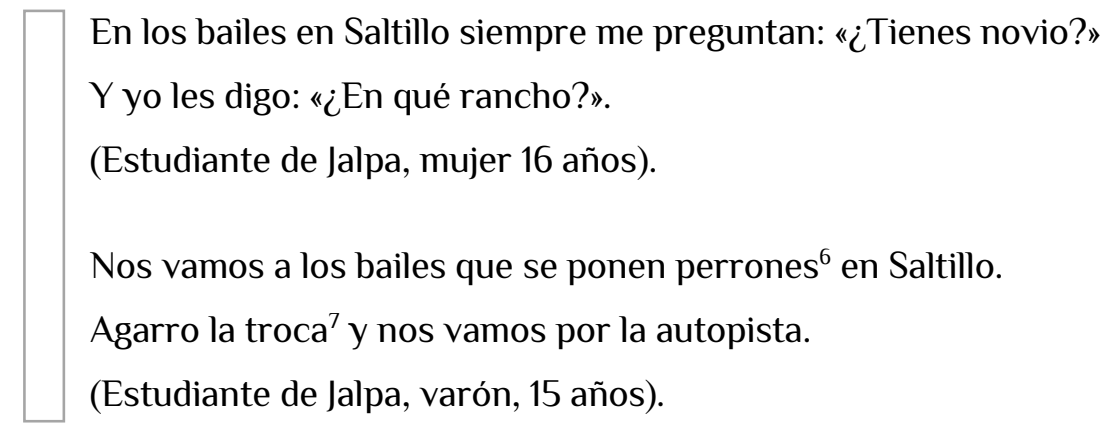

La categoría de juventud es un eje analítico que atraviesa y que se desdibuja en las actividades de lo/as estudiantes del ejido. Este grupo, de al menos quince hombres y mujeres, constantemente disputa su derecho a ser jóvenes en el ejido, debatiéndose entre las responsabilidades que no les permiten vivir una juventud idealizada -aquella que miran a través de las redes sociales y de la que, momentáneamente, forman parte en la ciudad vecina, donde los/as jóvenes solo se dedican a estudiar y a divertirse-. Sin embargo, esta imagen romántica del/la joven citadino/a, moderno/a y despreocupado/a no se aplica en los contextos rurales. En Jalpa, diversos factores dificultan dicha utopía, entre ellos, la cuestión etaria y los roles, problemas que si bien también aquejan a las juventudes de las grandes ciudades en los contextos rurales se agudizan. Así, es común observar que la niñez es una etapa fugaz, ya que desde edades tempranas las responsabilidades del universo adulto se yuxtaponen a los derechos que tanto niños/as como jóvenes deben poseer.

El trabajo infantil es una característica de las comunidades rurales y de los países en desarrollo. Según datos de la Organización para la Cooperación y el Desarrollo Económicos (OCDE), México es el segundo país de América Latina con más casos registrados de infantes que abandonan la escuela para dedicarse al trabajo. Según Pedro Orraca (2014), en México los hijos primogénitos tienen una mayor probabilidad de vincularse al mercado laboral que el resto de sus hermanos. En muchas comunidades rurales, el mercado laboral se establece por la necesidad de mantener las actividades familiares en el campo, condición que se perpetúa, entre otros factores, debido a la falta de oportunidades académicas y culturales. 
De tal modo, en contextos como el de Jalpa, donde el último grado académico es el bachillerato, el campo -y la maquila, ${ }^{8}$ en la ciudad- se convierten en las únicas dos opciones de vida viables, y para enfrentar esta etapa de su vida los/as jóvenes son preparados/as y condenados/as desde la niñez.

En escenarios no urbanos, la juventud es vista como un estadio fugaz que desde temprana edad se ubica más próximo a las actividades y a las responsabilidades de la vida adulta. En este sentido, es como si ser joven fuese un momento que es posible vivir solo en determinadas circunstancias y escenarios. Los/as jóvenes de Jalpa se encuentran en una disyuntiva permanente que, por un lado, los/as obliga a asumir roles que garanticen la supervivencia del ejido y que, por el otro, los/as lleva a mantener su propia lógica relacional con el territorio.

Para Micheletti, Saravia y Letelier (2019), la noción de rurbano se manifiesta también desde los imaginarios que se construyen cuando jóvenes y adultos/as navegan y se expresan en la red. La tecnología y el acceso a la red son potentes moduladores de lo que se desea para el territorio habitado, al tiempo que abren un espacio de confluencia en donde el ideal de lucha que manifiestan los/as adultos/as posee tanto valor como el ideal de diversión y de nostalgia que expresan sus jóvenes. Ambos grupos construyen imaginarios que muestran los modos de ser y de vivir en Jalpa. Los/as adultos/as, que poseen menores habilidades de lectoescritura, emplean la tecnología para fines políticos, comerciales y para enaltecer las bondades del territorio; los/as jóvenes utilizan los mismos servicios para aprender a maquillarse, para rifar e intercambiar productos traídos de la ciudad, para escuchar música y para organizar la asistencia colectiva a los bailes que se realizan en la ciudad.

Tal como mencionamos en líneas anteriores, rápidamente identificamos que la tecnología es un elemento de socialización importante y que, al mismo tiempo, ha generado en los/as jóvenes un cúmulo de deseos y de ideales de vida que los aleja -aparentemente- del mantenimiento de sus tradiciones en su comunidad y que los conduce hacia la construcción imaginaria de un nuevo territorio que se aparta del contexto rural para construirse en el marco de un contexto urbano. Sin embargo, los modos mediante los cuales lo/as habitantes del ejido comparten a través de la red sus experiencias en el ejido son también formas de hacer política en su territorio (Cornejo, 2017), pues ambos grupos son capaces de intervenir en la forma en la que desean que Jalpa sea conocido. En este sentido, ambos grupos 
abren la posibilidad de generar nuevos escenarios de pertenencia gracias al vector tecnológico que atraviesa gran parte de sus actividades cotidianas.

Imágenes del ejido:

temporalidad, vector tecnológico y heterocromía del tiempo

En El tiempo de lo visual (2015), Moxey refiere que las imágenes y el mundo no establecen una sola forma de exponer aquello que se mira; por lo tanto, debemos hablar de diferentes tiempos y lugares que se intersecan y se yuxtaponen formando parte del tiempo que habitamos. Esta heterocromía abre espectros para entender variaciones no lineales en la cultura visual contemporánea. Las imágenes del progreso mostradas a través de las redes son la mirada colonizada, pues expresan la forma de ver y de consumir la imagen desde un único artefacto y desde una única interfaz.

En este sentido, si bien las expresiones visuales de lo rural poseen características compartidas con sus símiles urbanas, exponen su propio derecho a generar una mirada propia, pues desde su contexto generan -desde la imitación- el modo en que quieren ser vistos (Mirzoeff, 2016, p. 2). Así, tanto los/as jóvenes como los/as adultos/as del ejido defienden su propio derecho a mirar y a ser mirados/as. Sus planteamientos invitan a dialogar con nuevas formas de entender los objetos visuales que se construyen en escenarios no hegemónicos pero que, al mismo tiempo, están impregnados por la misma textura globalizante que emana de la tecnología interconectada (Moxey, 2015).

Las imágenes que se amalgaman en la web son cohabitantes del mismo tiempo histórico. Por lo tanto, la imagen y la temporalidad son relevantes; en términos de Mirzoeff (Dussel, 2009), «la contra-visualidad es la posibilidad de afirmar una ciudadanía que puede crear un mapa de lo social, [y al mismo tiempo] un mapa visual de lo social» (p. 74).

En estos cruces, respecto a las diferencias en las modalidades de uso de los dispositivos y sus servicios, identificamos que no existe entre estos dos grupos -al menos, no de forma clara- un espacio de diálogo intergeneracional. Los roles etáreos y el universo adulto son factores preponderantes en la socialización de los/as jóvenes, y esta forma estructurante no deja espacio para que estos/as 
últimos/as exploren mediante sus propios mecanismos otras posibilidades de participación en el ejido. Esto se debe, por un lado, a la poca apertura de las fronteras etarias para establecer un diálogo que no sea estrictamente laboral y, por el otro, a que las actividades de recreación para lo/as jóvenes se desdibujan una vez que salen de la escuela para encarar el trabajo físico que está directamente relacionado con el mundo adulto [imágenes 6].

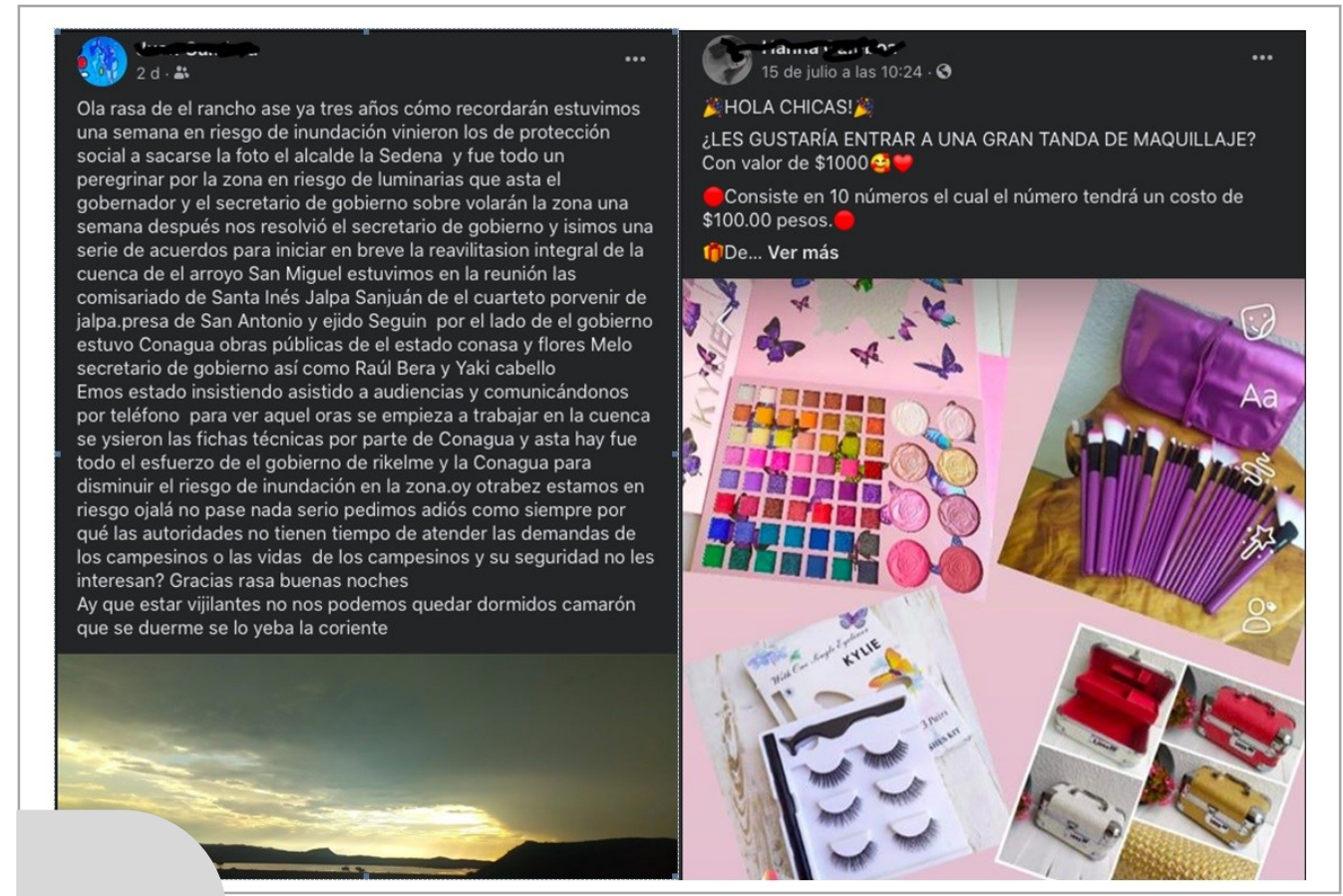

Imágenes 6 | Diferentes formas de uso de los servicios de mensajería instantánea. Fuente: registro propio

Este paradigma de vida es el de la supervivencia y el de los deberes en tanto tareas preconcebidas e inamovibles, y se realiza en tareas como vacunar a los cerdos, ensillar los caballos, pastorear a las cabras o tallar la lechuguilla. Un ejemplo claro es que fuera del escenario escolar, en el ejido no hay posibilidades para generar actividades que integren trabajo-diversión o deberes-entretenimiento, de allí que la noción de responsabilidad vinculada con el universo adulto se dibuja para los/as estudiantes como algo aburrido y que genera pesadumbre y rechazo.

Al mismo tiempo, la escuela es un escenario que se valora, principalmente, como un espacio de socialización para estar con pares, para reír y para compartir experiencias propias de su edad, y no necesariamente como un espacio de aprendizaje y de apertura a otras realidades posibles. El bachillerato de Jalpa es el 
único en más de cinco ejidos a la redonda, su plan de estudios integra en una sola aula los tres niveles -que se dividen en seis semestres-, y en un solo grupo se atiende a quince estudiantes, con edades que oscilan entre los 15 y los 18 años.

No obstante, aunque las características geográficas de Jalpa y sus formas de organización política y educativa reflejan algunas carencias, no es extraño observar tanto en los grupos de adultos/as como de jóvenes sendas de resistencia compartida que renuncian a la idea del abandono del territorio. Estos actos son visibles a partir de distintos elementos. En el caso del espacio virtual, se reflejan más características de similitud desde sus actividades cotidianas, principalmente, en las acciones que desempeñan en su relación con la tecnología interconectada a la red. Pues si bien ambos actores la emplean para actividades aparentemente distintas, el plexo que yace bajo estas acciones es el escenario en el cual pueden establecer modalidades de diálogo y construir conocimiento a través de las imágenes que producen del ejido.

Para Moxey (2015), es imperativo entender que la temporalidad se encuentra saturada de tiempos que orbitan a distintas velocidades y que organizan diversas cartografías culturales. De este modo, la temporalidad permite generar conocimiento desde las condiciones de producción de las imágenes y de su uso, pese al poder legitimado de las culturas dominantes que difunden estructuras temporales jerarquizadas que reproducen y que se erigen como los principales cánones mediante los cuales debe ser representado el mundo.

Las imágenes generadas en esta primera parte de la investigación nos permiten establecer cruces y nos abren escenarios de libertad creativa en un sentido esperanzador que arropa las posibilidades de construir otros relatos en una temporalidad hetero-crónica. Estos relatos imaginados y de posibilidades se erigen como escenarios de conquista desde las formas en las que los/as estudiantes de Jalpa observan su propio territorio. Estas formas de ver se muestran en las acciones de sus habitantes, porque se expresan tanto en la forma de luchar como en la forma de entretenerse, y ambas son dos modalidades de ser y de estar en el ejido.

Buenos días rasa de el rancho un saludo y otra ves presumiendo.

Pues resulta que cumplimos 40 años de casadas mi esposa y yo creo que todos los méritos se los merese pues no coalkiera aguanta tantos años con algien que cree en las personas y no cree en Dios se le agradece mucho el esfuerzo (Lider ejidal. Fragmento tomado de una publicación en Facebook). 
Pues cuando me despierto, lo primero que hago es revisar mis redes sociales y postear una foto, luego me levanto, me lavo la cara y me voy a la escuela. (Estudiante de Jalpa, varón, 17 años).

La tecnología móvil con capacidad de interconexión a la red se ha vuelto un elemento trascendental en casi todos los espacios de la vida cotidiana. En entornos urbanos y rurales la tecnología ha abierto puertas para introducirse, rápidamente, en la vida de sus habitantes. Las imágenes juveniles de Jalpa se construyen con los ideales observados tanto en la ciudad como en mundo virtual.

Hace apenas dos décadas, los escenarios digitales parecían pertenecer exclusivamente a contextos relacionados con las grandes ciudades, en donde los flujos de información se integraban a la velocidad y al dinamismo de sus habitantes. Sin embargo, a casi treinta años de la masificación de Internet en el mundo, los servicios de conectividad están disponibles para usuarios/as de casi cualquier rincón del planeta; catalizando con ello la generación exponencial de contenidos y de imágenes, pese a que la gama no parezca ser muy variada.

A inicios del siglo XXI, las hoy denominadas redes sociales ya evidenciaban, a través de las prácticas de sus usuarios/as, estilos de vida ligados, principalmente, a universos musicales, tal fue el caso de myspace y fotolog, redes en las cuales se reunían legiones de usuarios/as que compartían un mismo género musical y/o patrones de indumentaria específicos. En la actualidad, sin embargo, tanto los escenarios y los servicios como las lógicas de uso han desdibujado, en términos de la imagen producida, algunas fronteras socioeconómicas y territoriales y, en gran medida, han homologado diferencias entre usuarios/as, principalmente, las relacionadas con el consumo y con la producción de contenidos.

En este mismo tenor, la noción de tendencia o trend (por su nombre en inglés) ha establecido modos de usar/se y presentar/se en las redes a través de las pantallas; al mismo tiempo, la imagen-copia también ha simplificado las potencialidades que la misma tecnología posee. De forma irónica, en nuestros días contamos con potentes motores de búsqueda y con poderosos procesadores de datos que caben en la palma de la mano, pero que en su mayoría son utilizados para imitar y para elaborar contenidos no solo pobres en términos de calidad visual, sino que responden a una pobre oferta de posibilidades de variación y de diferencia. En términos de Moxey (2015), estamos ante la reiteración del discurso dominante 
que establece aquello que puede verse y lo que no. Estas modulaciones, entendidas por el mismo Moxey (2009) como giros visuales, se establecen desde la noción de control que el sujeto cree poseer sobre la condición de libertad de sus acciones. No obstante, este locus social está integrado por la constante interacción entre los regímenes de la visualidad, las instituciones y el cuerpo. Dicha integración establece los patrones de cómo ver/se, usar/se y mostrar/se a través de la tecnología interconectada.

En gran parte, las formas de ver son establecidas por las formas de usar la tecnología. En las últimas décadas, estas modalidades de uso han operado como las principales herramientas que lograron desdibujar las fronteras entre los espacios urbanos, semiurbanos y rurales. En nuestros días, dentro de la limitada oferta de posibilidades ${ }^{9}$ para generar contenidos a través de los servicios de redes sociales en Internet, no es extraño observar imágenes y videos elaborados desde grandes ciudades así como desde los más recónditos asentamientos y comunidades indígenas en diversas partes del mundo.

Estas posibilidades, las de generar imágenes a través de la tecnología, operan en términos de deseo como una causa inmanente en el sujeto que las posee, las produce, las significa y las comparte en un proceso que desdibuja las fronteras de lo diverso para radicarse en el universo de lo igual; es decir, el/la usuario/a productor/a elimina la diversidad fecunda para reproducir experiencias esclavizantes de su mirada conquistada. Tal es el caso de los contenidos sobre recetas de comidas, tutoriales de maquillaje, experiencias de viajes, memes, videos cortos y gifs, que poseen las condiciones de plasticidad y de adherencia por el código programático sobre el que operan. Esta cualidad de simpleza e inmediatez, permite que los contenidos generados puedan anclarse en distintos escenarios tanto urbanos como rurales que, al final del día, comparten una misma condición: el entretenimiento.

Del mismo modo que ocurre en las grandes ciudades, los/as jóvenes del ejido se duermen y se despiertan con el smartphone en la mano, ven tutoriales y comparten sus experiencias sobre fiestas, revisan sus redes sociales desde que se levantan y envían mensajes antes de acostarse. Hacen lo posible para salir del ejido no solo para divertirse en los bailes sino también para comprar datos y mantener la conexión con sus amigos/as dentro y fuera de Jalpa. Los/as adultos/as hacen lo propio. En el caso de uno de los líderes ejidales, utiliza Facebook para conocer el acontecer político 
y las luchas sociales en diferentes puntos del planeta, así como para mantener contacto con sus colegas y amigos, que también son miembros de colectivos sociales en distintas partes del mundo. Pese a sus carencias en ortografía, posee una sabiduría pasmosa y hace gala de ello al difundir movimientos de lucha y de resistencia, y al publicar imágenes del ejido; acciones que son importantes para mantener su condición de guardián del ejido.

Finalmente, para el equipo de investigación del proyecto «Comunidades Emergentes de Conocimiento y Procesos de Investigación/Creación Audiovisual» resulta imperativo reflexionar sobre las imágenes que hemos generado en el ejido, pues entendemos que estas formarán parte de los cimientos que nos permitirán establecer escenarios posibles para el diálogo intergeneracional entre sus habitantes y darán forma a los sistemas de información que estamos elaborando.

En este sentido, esperamos fortalecer los diálogos que nos permitan, junto con sus habitantes, establecer múltiples formas de entender, de valorar y de apropiarse del territorio, para, adicionalmente, poder validar las diferencias que sus actores tienen sobre el terruño, que es, al mismo tiempo, duro y hostil, pero también divertido y ameno. Somos conscientes de que este documento no ofrece respuestas totales; por el contrario, construye nuevos interrogantes que surgen a partir del trabajo de observación y de participación con algunos/as de los/as habitantes del ejido Jalpa. De tal modo, entendemos que abrir nuevas preguntas sobre el problema puede ser parte de su solución.

\section{Referencias}

Berardi, F. (2017). Futurabilidad. La era de la impotencia y el horizonte de la posibilidad. Ciudad Autónoma de Buenos Aires, Argentina:

Caja Negra.

Ley Agraria (1992). Dirección General de Servicios de Documentación, Información y Análisis, Secretaría de Servicios Parlamentarios, Cámara de Diputados del Honorable Congreso de la Unión.

Recuperado de http://www.diputados.gob.mx/LeyesBiblio/pdf/13_250618.pdf 
Cornejo, l. (Coord.) (2017). Juventud rural y juventud mayahablante. Acechar, observar e indagar sobre una temática emergente.

Ciudad de México, México: Universidad Autónoma Metropolitana.

Corduneanu, I. (2017). Jóvenes rurales, actitudes y participación política: un tema emergente. En I. Cornejo (Coord.), Juventud rural y juventud mayahablante. Acechar, observar e indagar sobre una temática emergente (pp. 25-56). Ciudad de México, México: Universidad Autónoma Metropolitana.

Dussel, I. (2009). Entrevista con Nicholas Mirzoeff. La cultura visual contemporánea: política y pedagogía para este tiempo. Propuesta Educativa, (31), 69-79. Recuperado de http://propuestaeducativa.flacso.org.ar/wpcontent/uploads/2019/12/entrevista_mirzoeff.pdf

Feixa, C. (2003). Del reloj de arena al reloj digital.

Sobre las temporalidades juveniles. Revista de Estudios sobre Juventud, 7(19), 6-27.

Instituto Nacional de Estadística y Geografía (INEGI). (2015).

Prontuario de información geográfica de los Estados Unidos Mexicanos.

Recuperado de

https://www.inegi.org.mx/app/buscador/default.html?q=coahuila

Micheletti, S., Saravia, F. y Letelier, F. (2019). Los contenidos del habitar rurbano. Prácticas, movilidad e identidades en las ciudades intermedias del Maule, Chile. Cuaderno Urbano. Espacio, cultura, sociedad, (27). http://dx.doi.org/10.30972/crn.27274121

Mirzoeff, N. (2016). Cómo ver el mundo. Una nueva introducción a la cultura visual. Barcelona, España: Paidós. 
Moxey, K. (2009). Los estudios visuales y el giro icónico (Trad. Roberto

Riquelme). Estudios visuales. Ensayo, teoría y crítica de la cultura

visual y el arte contemporáneo, (6), 8-27. Recuperado de

https://bibliodarq.files.wordpress.com/2013/11/4c-moxey-k-los-estudios-

visuales-y-el-giro-icc3b3nico.pdf

Moxey, K. (2015). El tiempo de lo visual. La imagen en la historia.

Ciudad Autónoma de Buenos Aires, Argentina: Sans Soleil.

Orraca, P. (2014). El trabajo infantil en México y sus causas.

Revista Problemas del Desarrollo, (45). Recuperado de

https://doi.org/10.1016/S0301-7036(14)70878-8

Silva, J. C. (2002). Juventud y tribus urbanas: en busca de la identidad.

Última década, 10(17), 117-130. Recuperado de

https://revistas.uchile.cl/index.php/UD/article/view/56009

Notas

1 La coordinación del proyecto (No. A1-S-8879) está a cargo de la Dra. Adriana Marcela Moreno Acosta, investigadora de la Universidad Autónoma de Coahuila.

2 Desde la perspectiva de la Red CIMAS, y su propuesta sobre metodologías participativas emergentes para conocer lo social, las derivas o transectos son los recorridos por el lugar con las personas que habitan un territorio, en donde tanto el equipo de investigación como los habitantes pueden descubrir características que no conocían del otro y con ello iniciar procesos de vinculación con menor carga de prejuicios.

3 La lechuguilla es una cactácea de la familia de los agaves. Sus hojas con espinas se cortan y se procesan por medios manuales o mecánicos para extraer las fibras, denominadas ixtle. Estas fibras se secan al sol y se utilizan para la industria manufacturera en la elaboración de cuerdas, cepillos, canastos, etc. El proceso de tallado y de secado puede durar hasta dos semanas y su precio de compra es de 80 pesos por kilo.

4 La región industrial y ganadera de la Laguna está conformada por los estados de Coahuila y de Durango. En este territorio, ubicado al norte de México, convergen 18 municipios y algunas de las empresas más grandes del continente en el rubro lácteo y de cerveza. Marcas como Lala y Corona tienen su sede central de producción en la región Lagunera. 
5 La mayoría de las viviendas tienen condiciones precarias, tanto en los tejados como en los muros y el suelo, $y$ la falta de puertas y ventanas no es extraña.

6 Término de uso coloquial en el norte de México que significa 'bueno' o 'bonito'.

7 En el norte de México, es común escuchar expresiones que mezclan el idioma inglés con el español para hacer referencia a objetos $\mathrm{y} / \mathrm{o}$ actividades con la finalidad de entenderlas como sinónimos; en este caso, la palabra «troca» proviene de la palabra «truck», que significa 'camioneta'.

8 En el ámbito económico, la maquila es un sistema de producción basado en zonas de procesamiento para la exportación. Una maquiladora, de ahí el término, transforma insumos intermedios provenientes del extranjero en objetos o en bienes terminados, que son devueltos a los países de origen para su comercialización a nivel mundial. En el caso de México, desde la firma del Tratado de Libre Comercio de América del Norte (TLCAN), hoy T-MEC, Tratado de Libre comercio México, Estados Unidos y Canadá, que entró en vigor en 1994, diversas regiones del país, sobre todo el Bajío y el Norte, son zonas de procesamiento y de ensamble de la industria automotriz.

9 Utilizamos el término limitante por la condición de monopolio que impera en los servicios de entretenimiento y de comunicación digital en nuestros días. Basta con entender la estructura de servicios de las empresas Apple, Facebook, Microsoft, Amazon y Alphabet quienes en conjunto dominan el mercado mundial de servicios tecnológicos. 